\title{
Comparing the incidence of hypoglycemia episodes in patients with type 2 diabetes and chronic kidney disease treated with insulin or glibenclamide
}

\section{ABSTRACT}

Introduction. Hypoglycemia is one of the side effects of glibenclamide, which is administered orally in people with diabetes. Hypoglycemia may occur easily due to the reduced metabolism of this drug in patients with chronic kidney disease. The aim of this study was to compare the incidence of hypoglycemia in patients with chronic kidney disease who were treated with glibenclamide or insulin.

Material and methods. In this study, 87 patients with type 2 diabetes and in stage 3-4 of chronic kidney disease (CKD) were examined. The patients were divided into two groups of glibenclamide $(\mathrm{N}=44)$ and insulin $(\mathrm{N}=43)$ based on the type of blood glucose-lowering therapy. Next, demographic data, serum creatinine level, number of hypoglycemic episodes over the last year and the amount of consumed drugs were recorded in the checklist. Finally, the data analysis was performed using the SPSS Software.

Results. There was no significant difference between the two groups in terms of age, estimated glomerular filtration rate (eGFR), weight, duration of diabetes and blood glucose control. In addition, it was indicated that $38 \%$ of patients in the glibenclamide group and $32 \%$ of patients in the insulin group had at least one hypoglycemic episode. Also, in those two

Address for correspondence:

Hossein Saghafi

Department of Internal Medicine,

Qom University of Medical Sciences, Qom, Iran

e-mail: hsaghafi@muq.ac.ir

Clinical Diabetology 2018, 7, 3, 159-163

DOI: $10.5603 /$ DK.2018.0012

Received: 24.12.2017

Accepted: 12.02 .2018 groups, there was no significant correlation between doses of the drug and the number of hypoglycemic episodes.

Conclusions. This study showed that there was no significant difference between the patients with chronic kidney disease who were treated with insulin and those patients who were treated with glibenclamide in terms of number of symptomatic hypoglycemic episodes. (Clin Diabetol 2018; 7, 3: 159-163)

Key words: glyburide, kidney disease, chronic, insulin, hypoglycemia, diabetes mellitus

\section{Introduction}

Diabetes is the most common endocrine disorders in the world and its prevalence is rising (in 1980, 4.7\% of individuals over the age of 18 were afflicted with diabetes but the latter percentage increased up to $8.5 \%$ in 2014). In 2015, it was estimated that 1.5 million deaths were directly caused by diabetes. In 2012, 2.2 million deaths were associated with high blood glucose [1].

The renal failure is one of the complications of diabetes and several studies indicate that the primary cause of renal failure is diabetes among $25 \%$ of patients with renal failure and $50 \%$ of patients with end stage renal disease (ESRD) $[2,3]$. It is impossible to prevent the progression of renal failure and other complications of diabetes, except by controlling the blood glucose in these patients. Many patients tend to get oral glucoselowering drugs. According to the National Health and Nutrition Examination Survey, $62.9 \%$ of patients with CKD stages 4-5 receive at least one oral glucose-low- 
ering drug [4]. The metabolism of many drugs widely used in the treatment of diabetes is dependent on the kidney. As a result, these drugs are contraindicated or they require dose adjustments to prevent hypoglycemic episodes, lactic acidosis and other possible complications. Besides, review studies and guidelines do not adopt any definite approach towards using these drugs [5]. As such, the clinical opinions of physicians are different in the use of these drugs. A study was conducted on 301 patients in stage 3 to stage 5 of CKD and the results indicated that, based on the guideline on chronic kidney disease patients [6], 53\% of them took drug or doses outside of the proposed recommendation, of which $24.4 \%$ were treated with the glibenclamide [7]. Another study was conducted in France and it was found that the general practitioners and diabetes specialists did not take into account the proposed recommendations and, thus, they prescribed metformin for $63 \%$ of patients with stage 3 of CKD and $33 \%$ of patients with stage 4 of CKD. Also, they prescribed sulfonylureas for $51 \%$ and $61 \%$ of patients with stage 3 and stage 4 of CKD, respectively [8].

As noted, sulfonylureas are among the drugs that are used regardless of proposed recommendations. Although these drugs are involved in controlling blood glucose by stimulating the secretion of insulin, the same mechanism can put patients at increased risk for hypoglycemia. Actually, the risk of hypoglycemia increases in patients who have decreased level of GFR. The cause of this increased risk in patients with renal failure can be summarized as follows: 1) decreased level of insulin clearance and the oral drug itself [5] and 2) decreased level of gluconeogenesis due to loss of kidney mass [9]. For this reason, many researchers have forbidden the use of glibenclamide in patients with chronic kidney disease stages 3-5 [10].

Considering the refusal of many patients to accept insulin therapy and the costly use of existing oral drugs in the treatment of renal failure, many patients still tend to use these drugs, despite being aware of the side effects of oral drugs such as glibenclamide. Accordingly, the aim of this study was to compare the prevalence of hypoglycemia in patients with renal failure who were treated with glibenclamide and patients who received insulin.

\section{Materials and methods}

The study was conducted in a historical cohort design. As such, the medical records of all diabetic patients in stage 3 and stage 4 of CKD, who were referred to nephrology clinics from March 21, 2011 to September 21, 2015 in Qom province, were reviewed. In total, the medical records of 107 patients treated with glibenclamide or insulin were extracted. Next, the medical records of patients that were followed for at least 1 year to control the blood glucose and were checked up at least for 10 sessions during this period were selected. As such, other medical records were excluded from the study. Finally, 87 medical records were included in the study based on the entry criteria for the study. The medical records of 20 other patients were also examined. According to available data and after contacting the patients, it was found that there was no significant difference between these 20 medical records and the 87 medical records in terms of hypoglycemia occurrence.

Those patients who presented with renal failure for at least 3 months or more were diagnosed as CKD patients. Accordingly, all patients who were at stage 3 of CKD or higher were included in the study. Besides, the patients' GFR was calculated using the Cockcroft-Gault formula based on gender, weight, age and serum creatinine $(\mathrm{GFR}=\{((140$-age $) \times$ weight $) /(72 \times \mathrm{SCr})\} \times$ 0.85 (if female)).

Furthermore, the patients' medical records were investigated in terms of demographic variables, type of diabetes treatment and incidence of hypoglycemia. Given the one-year follow up, it was attempted to make use of neurological and neuroglycopenic symptoms as well as patients' remarks in order to determine the incidence of hypoglycemia. Hypoglycemia episode is defined as an event with symptoms of hypoglycemia which was associated with a blood glucose level below $50 \mathrm{mg} / \mathrm{dL}$ or prompt recovery after oral carbohydrate ingestion or intravenous glucose administration.

All patients were informed about the side effects of medications and hypoglycemia symptoms at the onset of their treatment, and in each visit they were asked about hypoglycemia symptoms and episodes.

Having collected the required information, all the data was analyzed using the SPSS Statistical Software (Version 22). Regarding the quantitative variables, it was decided to calculate the mean and standard deviation. Given the qualitative variables, it was endeavored to calculate the absolute and relative frequency. In this analysis, frequency distribution and prevalence indices as well as statistical T-test and Chi-Square Test with a significant level of less than 0.05 were used. In addition, the logistic regression was implemented to investigate the impact of forenamed factors, such as type of treatment, on hypoglycemia. Finally, the Spearman correlation coefficient was used to check the correlation between the drug dose and number of episodes.

The information was extracted confidentially and the results were announced in a group-based format. Patients were fully aware of complications of gliben- 
Table 1. Distribution of patients according to the type and dose of treatment

\begin{tabular}{lccc}
\hline Treatment & Frequency & Percent & $\begin{array}{c}\text { Cumulative } \\
\text { percent }\end{array}$ \\
\hline Glibenclamide $(5 \mathrm{mg})$ & 13 & 14.9 & 14.9 \\
Glibenclamide $(7.5 \mathrm{mg})$ & 5 & 5.7 & 20.6 \\
Glibenclamide $(10 \mathrm{mg})$ & 8 & 9.2 & 29.8 \\
Glibenclamide $(12.5 \mathrm{mg})$ & 1 & 0.1 & 29.9 \\
Glibenclamide $(15 \mathrm{mg})$ & 6 & 6.9 & 36.8 \\
Glibenclamide $(20 \mathrm{mg})$ & 11 & 12.6 & 49.4 \\
Insulin & 43 & 50.6 & 100 \\
\hline
\end{tabular}

clamide, but their unwillingness to use insulin led the researchers to treat them with glibenclamide.

\section{Results}

In this study, 87 diabetic patients in stage 3 and 4 of CKD were studied. In fact, 43 patients were treated with insulin and 44 patients received glibenclamide. Table 1 shows the distribution of patients according to the type and the dose of treatment. The patients were divided into two groups of glibenclamide $(\mathrm{N}=44)$ and insulin ( $\mathrm{N}=43$ ) based on the type of blood glucose-lowering therapy.

It was found that, except for the gender based distribution, there was no significant difference between the two groups regarding the study variables (age, GFR, weight and duration of diabetes). Besides, it was found that there was no significant difference in blood glucose control between two groups of patients (Tab. 2).

It was indicated that 17 patients (38.6\%) in the glibenclamide treated group and 14 patients (32.6\%) in the insulin treated group experienced symptomatic hypoglycemia within a one-year of follow up. However, the findings indicated that the difference was not statistically significant $(p=0.557)$. This study showed that there was no significant difference between the two groups in terms of number of hypoglycemic episodes. The mean number of hypoglycemic episodes in the glibenclamide-treated and insulin-treated groups were $1.89 \pm 1.33$ and $1.98 \pm 1.61(p=0.776)$ respectively.

No correlation was found between glibenclamide dose $(r=0.103, p=0.504)$ or insulin dose $(r=0.124$, $p=0.253$ ) and the number of hypoglycemic episodes based on the result of the Spearman correlation coefficient.

The logistic regression showed that, among the variables studied in this study, there was only a significant relationship between patients' age and incidence of hypoglycemia (Tab. 3).

\section{Discussion}

This study was conducted due to observation thaat patients with renal failure are willing to use glibenclamide in spite of its most important complication, hypoglycemia. Despite the contraindication to use

Table 2. Comparison between the two groups regarding the under study variables

\begin{tabular}{|c|c|c|c|}
\hline Variable & Glibenclamide group & Insulin group & p-value* \\
\hline Male to female ratio & 2.76 & 1.05 & 0.038 \\
\hline Age (year), mean \pm SD & $69.02 \pm 9.77$ & $64.58 \pm 17.48$ & 0.146 \\
\hline Weight [kilogram], mean \pm SD & $75.73 \pm 12.16$ & $75.37 \pm 14.6$ & 0.902 \\
\hline Diabetes duration (year), mean \pm SD & $13.43 \pm 8.33$ & $15.1 \pm 10.52$ & 0.360 \\
\hline GFR $\left[\mathrm{mL} / \mathrm{min} / 1.73 \mathrm{~m}^{2}\right]$, mean $\pm \mathrm{SD}$ & $35.57 \pm 16.37$ & $31.82 \pm 15.95$ & 0.282 \\
\hline FBG $[\mathrm{mg} / \mathrm{dL}]$, mean $\pm \mathrm{SD}$ & $110.02 \pm 61.4$ & $120.07 \pm 77.4$ & 0.547 \\
\hline $\mathrm{HbA}_{1 \mathrm{c}}$ (percent), mean $\pm \mathrm{SD}$ & $5.54 \pm 3.66$ & $5.32 \pm 3.67$ & 0.774 \\
\hline
\end{tabular}

*P-value with 2-tailed, unpaired t-test. FBG — fasting blood glucose

Table 3. Effects of study variables on hypoglycemic episode by logistic regression

\begin{tabular}{|c|c|c|c|c|c|c|c|c|}
\hline & \multirow[t]{2}{*}{ B } & \multirow[t]{2}{*}{ S.E. } & \multirow[t]{2}{*}{ Wald } & \multirow[t]{2}{*}{ df } & \multirow[t]{2}{*}{ Sig. } & \multirow[t]{2}{*}{$\operatorname{Exp}(B)$} & \multicolumn{2}{|c|}{ 95\% C.I. for EXP(B) } \\
\hline & & & & & & & Lower & Upper \\
\hline Treatment type (glibenclamide) & 0.039 & 0.478 & 0.007 & 1 & 0.936 & 1.039 & 0.408 & 2.651 \\
\hline Gender (male) & 0.457 & 0.502 & 0.831 & 1 & 0.362 & 1.580 & 0.591 & 4.224 \\
\hline Age (year) & 0.046 & 0.024 & 3.857 & 1 & 0.050 & 1.048 & 1.000 & 1.097 \\
\hline GFR [mL/min] & 0.005 & 0.015 & 0.095 & 1 & 0.757 & 1.005 & 0.976 & 1.034 \\
\hline Constant & -4.229 & 1.815 & 5.429 & 1 & 0.020 & 0.015 & & \\
\hline
\end{tabular}

S.E. — standard error; df — degrees of freedom; Sig. — significance 
glibenclamide in patients with CKD (Stage 3 onwards), many patients do not accept insulin therapy due to problems they face in using such a drug. On the other hand, oral antidiabetic drugs used in renal failure are either not available or at a higher cost. The results of this study indicated that many patients still tended to use these drugs, despite being aware of the side effects of oral drugs such as glibenclamide. Similarly, previous studies have shown that $18 \%$ to $61 \%$ of patients in stage 3 and higher stages of CKD have been treated with sulfonylureas, which has been a forbidden practice $[7,8,11]$.

This non-compliance with the guidelines can be attributed to different reasons. In some studies, part of this lack of compliance was attributed to physicians' lack of knowledge and information. However, in the present study, the physicians and patients were aware of the contraindications to the drug use. Other causes have also been mentioned in studies; for example, patients argue that oral drugs are effective and easier to use and, unlike insulin, the oral drugs do not require daily doses adjustment. Insulin administration is associated with high risk of hypoglycemia in patients with renal failure $[9,12,13]$.

The results of this study did not show a significant difference between insulin treated and glibenclamide treated groups in terms of incidence of symptomatic hypoglycemia. However, previous studies have shown different results in this regard. Studies conducted on diabetic patients with normal kidney function have reported hypoglycemia rates between 0.2 and 1.8 in return for 100 person-years among users of sulfonylurea [14-16]. Regarding the other five studies that examined hypoglycemia caused by sulfonylureas in patients with renal failure, it was indicated that one study, similar to the present one, did not show any association between glibenclamide consumption and hypoglycemia [17]. However, the other four studies showed that the risk of hypoglycemia was higher in patients who used sulfonylureas than those patients who used other drugs [18-20].

Van Dalem et al. showed that there was an association between using sulfonylureas and the risk of hypoglycemia. Actually, the incidence rates of hypoglycemia in patients who have just started taking drug and those who have recently started taking the drug were 13.5 in 1000 person-years and 4.6 in 1000 person-years, respectively. Besides, they found that the incidence rate of hypoglycemia in patients who already took drug was 0.6 in 1000 person-years [21]. Given the present study, it was indicated that since all patients were already treated with these drugs, the difference between the present study and the rest of the studies could be attributed to the former reason.
There are some evidences that argue that sulfonylureas should not be used in patients with chronic kidney disease stage 3-5. For example, researchers believe that the risk for hypoglycemia is high in patients with renal failure because these patients are characterized with reduced clearance of sulfonylureas and insulin. On the other hand, due to decreased level of renal gluconeogenesis, these patients can deal with hypoglycemia to a lesser extent and power. Also, reduced level of appetite caused by uremia can also increase the risk of hypoglycemia in these patients [17, 22-24]. Furthermore, studies have shown that severe hypoglycemia can debilitate the prognosis of these patients in that the mortality rate of patients who once experienced severe hypoglycemia is 1.4 times more than that of the rest of the patients [25]. Also, the risk of death is very high over 90 days after a severe hypoglycemic attack [26].

Conversely, there are some evidences (e.g. the results of the present study) that undermine the absolute ban on using sulfonylureas (e.g. glibenclamide) in patients in stage 3 of CKD and higher. Weir et al. undertook a nested case-control study and found that there was no relationship between renal failure and the risk of hypoglycemia caused by glibenclamide [17]. Interestingly, the studies that showed that there was a relationship between death and hypoglycemia could not prove that the latter relationship was a causal one [27]. Besides, the pharmacokinetic studies conducted on glibenclamide showed that there was no correlation between creatinine clearance $\left(29-131 \mathrm{ml} / \mathrm{min} / 1.73 \mathrm{~m}^{2}\right.$ ) and glibenclamide clearance [28].

\section{Conclusions}

Regarding the findings of this study and the results of similar recent studies on such oral glucose-lowering drugs as glibenclamide, it can be argued that the ban on using sulfonylureas in CKD of stage 3 onwards can be revised.

It seems that failure to compare the severity of hypoglycemia in the two groups and the lack of investigation of patients' survival can be considered among the limitations of this study. Thus, it is suggested that further studies can be conducted on this subject. If this misleading belief is rejected, the physicians can prescribe glibenclamide as a cheap and less side effect drug in many diabetic patients who are diagnosed with chronic kidney disease caused by diabetic nephropathy.

\section{Acknowledgments}

This article is based on a thesis, which was approved at Qom University of Medical Sciences.

\section{Conflict of interest}

None declared. 


\section{REFERENCES}

1. Organization WH. Health topic — Diabetes Mellitus, 2015. www. who.int/topics/diabetes_mellitus/en/ (2015).

2. Cooper L. USRDS. 2001 Annual Data Report. Nephrol News Issues. 2001; 15(10): 31, 34-35, 38 passim, indexed in Pubmed: 12098974.

3. Mirchi E, Saghafi $H$, Gharehbeglou M, et al. Association Between 25-Hydroxyvitamin D Level and Inflammatory and Nutritional Factors in Hemodialysis and Peritoneal dialysis Patients in Qom, Iran. Iran J Kidney Dis. 2016; 10(4): 205-212, indexed in Pubmed: 27514767.

4. Koro CE, Lee BoH, Bowlin SJ. Antidiabetic medication use and prevalence of chronic kidney disease among patients with type 2 diabetes mellitus in the United States. Clin Ther. 2009; 31(11): 2608-2617, doi: 10.1016/j.clinthera.2009.10.020, indexed in Pubmed: 20110005.

5. Kajbaf F, Arnouts $P$, de Broe M, et al. Metformin therapy and kidney disease: a review of guidelines and proposals for metformin withdrawal around the world. Pharmacoepidemiol Drug Saf. 2013; 22(10): 1027-1035, doi: 10.1002/pds.3501, indexed in Pubmed: 23960029.

6. Guideline development group. Clinical Practice Guideline on management of patients with diabetes and chronic kidney disease stage $3 \mathrm{~b}$ or higher (eGFR $<45 \mathrm{~mL} / \mathrm{min}$ ). Nephrol Dial Transplant. 2015; 30 Suppl 2: ii1-142, doi: 10.1093/ndt/gfv100, indexed in Pubmed: 25940656.

7. Muller C, Dimitrov $Y$, Imhoff $O$, et al. CERRENE, CERRENE study group. Oral antidiabetics use among diabetic type 2 patients with chronic kidney disease. Do nephrologists take account of recommendations? J Diabetes Complications. 2016; 30(4): 675-680, doi: 10.1016/j.jdiacomp.2016.01.016, indexed in Pubmed: 26900098.

8. Penfornis A, Blicklé JF, Fiquet B, et al. How are patients with type 2 diabetes and renal disease monitored and managed? Insights from the observational OREDIA study. Vasc Health Risk Manag. 2014; 10: 341-352, doi: 10.2147/VHRM.S60312, indexed in Pubmed: 24966684.

9. Lalau JD, Arnouts $P$, Sharif A, et al. Metformin and other antidiabetic agents in renal failure patients. Kidney Int. 2015; 87(2): 308-322, doi: 10.1038/ki.2014.19, indexed in Pubmed: 24599253.

10. Betônico CCR, Titan SMO, Correa-Giannella ML, et al. Management of diabetes mellitus in individuals with chronic kidney disease: therapeutic perspectives and glycemic control. Clinics (Sao Paulo). 2016; 71(1): 47-53, doi: 10.6061/clinics/2016(01)08, indexed in Pubmed: 26872083.

11. Solini A, Penno G, Bonora E, et al. Renal Insufficiency and Cardiovascular Events Study Group. Age, renal dysfunction, cardiovascular disease, and antihyperglycemic treatment in type 2 diabetes mellitus: findings from the Renal Insufficiency and Cardiovascular Events Italian Multicenter Study. J Am Geriatr Soc. 2013; 61(8): 1253-1261, doi: 10.1111/jgs.12381, indexed in Pubmed: 23889588.

12. Mak RH, DeFronzo RA. Glucose and insulin metabolism in uremia. Nephron. 1992; 61(4): 377-382, doi: 10.1159/000186953, indexed in Pubmed: 1501732.

13. Rave K, Heise T, Pfützner A, et al. Impact of diabetic nephropathy on pharmacodynamic and Pharmacokinetic properties of insulin in type 1 diabetic patients. Diabetes Care. 2001; 24(5): 886-890, doi: 10.2337/diacare.24.5.886, indexed in Pubmed: 11347749 .

14. van Staa T, Abenhaim L, Monette J. Rates of hypoglycemia in users of sulfonylureas. J Clin Epidemiol. 1997; 50(6): 735-741, doi: 10.1016/s0895-4356(97)00024-3, indexed in Pubmed: 9250272.

15. Leese GP, Wang J, Broomhall J, et al. DARTS/MEMO Collaboration. Frequency of severe hypoglycemia requiring emergency treatment in type 1 and type 2 diabetes: a population-based study of health service resource use. Diabetes Care. 2003; 26(4): 1176-1180, doi: 10.2337/diacare.26.4.1176, indexed in Pubmed: 12663593.

16. Stahl M, Berger W. Higher incidence of severe hypoglycaemia leading to hospital admission in Type 2 diabetic patients treated with long-acting versus short-acting sulphonylureas. Diabet Med. 1999; 16(7): 586-590, doi: 10.1046/j.1464-5491.1999.00110.x, indexed in Pubmed: 10445835.

17. Weir MA, Gomes $T$, Mamdani M, et al. Impaired renal function modifies the risk of severe hypoglycaemia among users of insulin but not glyburide: a population-based nested case-control study. Nephrol Dial Transplant. 2011; 26(6): 1888-1894, doi: 10.1093/ /ndt/gfq649, indexed in Pubmed: 20974644.

18. Holstein A, Hammer C, Hahn M, et al. Severe sulfonylurea-induced hypoglycemia: a problem of uncritical prescription and deficiencies of diabetes care in geriatric patients. Expert Opin Drug Saf. 2010; 9(5): 675-681, doi: 10.1517/14740338.2010.492777, indexed in Pubmed: 20553106.

19. Schloot NC, Haupt A, Schütt M, et al. Risk of severe hypoglycemia in sulfonylurea-treated patients from diabetes centers in Germany/ /Austria: How big is the problem? Which patients are at risk? Diabetes Metab Res Rev. 2016; 32(3): 316-324, doi: 10.1002/ /dmrr.2722, indexed in Pubmed: 26409039.

20. Greco D, Pisciotta M, Gambina F, et al. Severe hypoglycaemia leading to hospital admission in type 2 diabetic patients aged 80 years or older. Exp Clin Endocrinol Diabetes. 2010; 118(4): 215-219, doi: 10.1055/s-0029-1241823, indexed in Pubmed: 20072965.

21. van Dalem J, Brouwers MC, Stehouwer CDA, et al. Risk of hypoglycaemia in users of sulphonylureas compared with metformin in relation to renal function and sulphonylurea metabolite group: population based cohort study. BMJ. 2016; 354: i3625, doi: 10.1136/bmj.i3625, indexed in Pubmed: 27413017.

22. Gerich JE, Meyer C, Woerle HJ, et al. Renal gluconeogenesis: its importance in human glucose homeostasis. Diabetes Care. 2001; 24(2): 382-391, doi: 10.2337/diacare.24.2.382, indexed in Pubmed: 11213896.

23. Biesenbach G, Raml A, Schmekal B, et al. Decreased insulin requirement in relation to GFR in nephropathic Type 1 and insulin-treated Type 2 diabetic patients. Diabet Med. 2003; 20(8): 642-645, doi: 10.1046/j.1464-5491.2003.01025.x, indexed in Pubmed: 12873291.

24. Snyder RW, Berns JS. Use of insulin and oral hypoglycemic medications in patients with diabetes mellitus and advanced kidney disease. Semin Dial. 2004; 17(5): 365-370, doi: 10.1111/j.08940959.2004.17346.x, indexed in Pubmed: 15461745.

25. Bonds DE, Miller ME, Bergenstal RM, et al. The association between symptomatic, severe hypoglycaemia and mortality in type 2 diabetes: retrospective epidemiological analysis of the ACCORD study. BMJ. 2010; 340: b4909, doi: 10.1136/bmj.b4909, indexed in Pubmed: 20061358.

26. Seaquist ER, Anderson J, Childs B, et al. Hypoglycemia and diabetes: a report of a workgroup of the American Diabetes Association and the Endocrine Society. Diabetes Care. 2013; 36(5): 1384-1395, doi: 10.2337/dc12-2480, indexed in Pubmed: 23589542.

27. Yun JS, Ko SH. Risk Factors and Adverse Outcomes of Severe Hypoglycemia in Type 2 Diabetes Mellitus. Diabetes Metab J. 2016; 40(6): 423-432, doi: 10.4093/dmj.2016.40.6.423, indexed in Pubmed: 27766794.

28. Pearson JG, Antal EJ, Raehl CL, et al. Pharmacokinetic disposition of 14C-glyburide in patients with varying renal function. Clin Pharmacol Ther. 1986; 39(3): 318-324, doi: 10.1038/clpt.1986.46, indexed in Pubmed: 3081293. 